\title{
No heart for paediatric heart transplantation in Hong Kong
}

\author{
$\mathrm{KL} \mathrm{Hon}^{1}{ }^{\text {*, }}$ MB, BS, MD, Karen KY Leung ${ }^{1}$, MB, BS, MRCPCH, CC Au', MB, BS, MRCPCH, ZG Chen², MD \\ ${ }^{1}$ Department of Paediatrics and Adolescent Medicine, The Hong Kong Children's Hospital, Kowloon Bay, Hong Kong \\ ${ }^{2}$ Department of Pediatrics, The Third Affiliated Hospital of Sun Yat-sen University, Guangzhou, China
}

* Corresponding author: ehon@hotmail.com

Hong Kong Med J 2020;26:457-8

https://doi.org/10.12809/hkmj198103

On 19 July 2019, it was reported that a 20-month-old boy with restrictive cardiomyopathy due to a rare genetic disease and multiorgan failure had undergone successful heart transplant, making him the youngest-ever such patient in Hong Kong. ${ }^{1}$ It is inconceivable why the numbers of donated organs have declined in recent years, nor why Hong Kong Chinese parents rarely donate the organs of their brainstem-dead (BSD) children, despite the potential lifesaving benefit to other children..$^{2-6}$ In a local survey on the knowledge and attitudes towards BSD among university undergraduates, the respondents' overall knowledge of BSD was unsatisfactory. ${ }^{2}$ Only $24 \%$ of respondents knew that BSD was the equivalent of legal death in Hong Kong. Among those who agreed that life support treatment could be withdrawn in the event that they themselves were diagnosed as BSD, only $70 \%$ and $76 \%$ would permit life support to be withdrawn from a family member or a stranger, respectively. ${ }^{2}$ The scenario for a child is unknown but likely worse. Adequate explanation and counselling are important to facilitate family members in coping with this important end-of-life issue. ${ }^{2}$

Over a 16 -year period, 22 patients $(17.3 \%)$ of all deaths in a paediatric intensive care unit were diagnosed with BSD. ${ }^{7}$ Among them, the authors recall only four cases of organ donation and included Western and Japanese families. The belief that the body of a child must remain integral with no cutting-out of internal organs is a taboo among local Chinese parents and may be a major obstacle to paediatric organ donation. Such cultural beliefs can take years or even decades to change.

Apart from personal and cultural beliefs, decisions by family members on organ donation are affected by multiple factors, including prior exposure to organ donation information, interaction with the medical team, and the person who first mentions the possibility. ${ }^{8}$ Acceptance of organ donation is directly related to the end-of-life experience and grief process ${ }^{9}$; thus, an experienced organ donation coordinator should be informed early to provide open and non-directional counselling and support to the family to increase their acceptance. Clear protocols in identification for possible donors and organ donation processes should also be in place.
Regular educational updates should be provided to doctors and nurses, especially intensivists. Under the current Hospital Authority guidelines in Hong Kong, the BSD criteria do not include children aged $<2$ years. This definition could be re-evaluated to increase the numbers of potential donors; guidelines for diagnosing BSD in children aged $<2$ years are available internationally, including in the United Kingdom, United States, Canada, and Australia. Some countries have adopted an 'opt-out' system for organ donation, and a cross-country study has shown that presumed consent countries have a $25 \%$ to $50 \%$ higher cadaveric donation rate. ${ }^{10}$

The above suggestions might increase the supply of the donor hearts only marginally. The major challenge in paediatric heart transplant is the size, as it has to be size-matched, and this makes the availability even more scarce. The way forward should be developing alternative replacements. Bioprinting of a functional artificial heart will be the ultimate breakthrough in heart transplant; however, there are still many challenges to overcome. Autologous induced pluripotent stem cells might offer new possibilities for building immune-compatible hearts for patients, bypassing the complications associated with heart transplant. ${ }^{11}$ Other options include developing smaller implantable ventricular assist devices for the paediatric patients, in order for patients awaiting transplant to be treated in an out-patient setting with fewer complications. The Jarvik 2015 15mm (Jarvik Heart, Inc., New York [NY], United States) is the only implantable ventricular assist device designed specifically for paediatric patients, and it is currently undergoing clinical trials.

If more donor hearts can be made available, heart transplants might even become an alternative to the treatment of complex congenital heart disease, especially in defects requiring staged operations with known high morbidity and mortality. Artificial hearts might be an answer, but it will take another 10 to 20 years before this becomes a realistic option. Until then, stories of successful paediatric heart transplant operations can hopefully raise public awareness and increase the parental acceptance in organ donation. 


\section{Author contributions}

All authors contributed to the concept or design, drafting, and critical revision of the manuscript for important intellectual content. All authors had full access to the data, contributed to the article, approved the final version for publication, and take responsibility for its accuracy and integrity.

\section{Conflicts of interest}

As an editor of the journal, KL Hon was not involved in the peer review process. Other authors have no conflicts of interest to disclose for this manuscript.

\section{Funding/support}

This commentary received no specific grant from any funding agency in the public, commercial, or not-for-profit sectors.

\section{References}

1. Toddler suffering from rare genetic disease undergoes successful heart transplant, making him the youngest ever such patient in Hong Kong. South China Morning Post. 19 Jul 2019. Available from: https://www.scmp.com/news/ hong-kong/health-environment/article/3019350/toddlersuffering-rare-genetic-disease-undergoes. Accessed $20 \mathrm{Jul}$ 2019.

2. Leung KK, Fung CO, Au CC, Chan DM, Leung GK. Knowledge and attitudes toward brain stem death among university undergraduates. Transplant Proc 2009;41:146972.
3. Cheung TK, Cheng TC, Wong LY. Willingness for deceased organ donation under different legislative systems in Hong Kong: population-based cross-sectional survey. Hong Kong Med J 2018;24:119-27.

4. Cheung CY, Pong ML, Au Yeung SF, Chau KF. Factors affecting the deceased organ donation rate in the Chinese community: an audit of hospital medical records in Hong Kong. Hong Kong Med J 2016;22:570-5.

5. Tafran K. In search of the best organ donation legislative system for Hong Kong: further research is needed. Hong Kong Med J 2018;24:318-9.

6. Hon KL, Poon TC, Wong W, et al. Prolonged non-survival in PICU: does a do-not-attempt-resuscitation order matter. BMC Anesthesiol 2013;13:43.

7. Hon KL, Tse TT, Au CC, et al. Brain death in children: a retrospective review of patients at a paediatric intensive care unit. Hong Kong Med J 2020;26:120-6.

8. Rodrigue JR, Cornell DL, Howard RJ. Pediatric organ donation: what factors most influence parents' donation decisions? Pediatr Crit Care Med 2008;9:180-5.

9. Hoover SM, Bratton SL, Roach E, Olson LM. Parental experiences and recommendations in donation after circulatory determination of death. Pediatr Crit Care Med 2014;15:105-11.

10. Abadie A, Gay S. The impact of presumed consent legislation on cadaveric organ donation: a cross-country study. J Health Econ 2006;25:599-620.

11. Lundberg MS, Baldwin JT, Buxton DB. Building a bioartificial heart: Obstacles and opportunities. J Thorac Cardiovasc Surg 2017;153:748-50.

\section{Answers to CME Programme Hong Kong Medical Journal August 2020 issue}

Hong Kong Med J 2020;26:289-93

I. Patterns of COVID-19 on computed tomography imaging
A
1. False
2. True
3. False
4. False
5. True
B
1. True
2. False
3. False
4. True
5. True

Hong Kong Med J 2020;26:294-303

\section{Warfarin control in Hong Kong clinical practice: a single-centre observational study}
A
1. False
2. True
3. True
4. False
5. False
B
1. False
2. True
3. True
4. True
5. True 